\section{EMBRYRIDDLE}

Aeronautical University

SCHOLARLY COMMONS
Journal of Aviation/Aerospace Education \& Research

Volume 19

Number 3 JAAER Spring 2010

Article 4

Spring 2010

\title{
Effects of Repetitive End Cleaning on Multimode Plastic Fiber Optic Cable Performance
}

Dennis R. Hannon

Follow this and additional works at: https://commons.erau.edu/jaaer

\section{Scholarly Commons Citation}

Hannon, D. R. (2010). Effects of Repetitive End Cleaning on Multimode Plastic Fiber Optic Cable Performance. Journal of Aviation/Aerospace Education \& Research, 19(3). https://doi.org/10.15394/ jaaer.2010.1364

This Article is brought to you for free and open access by the Journals at Scholarly Commons. It has been accepted for inclusion in Journal of Aviation/Aerospace Education \& Research by an authorized administrator of Scholarly Commons. For more information, please contact commons@erau.edu. 


\title{
EFFECTS OF REPETITIVE END CLEANING ON MULTIMODE PLASTIC FIBER OPTIC CABLE PERFORMANCE
}

\author{
Dennis R. Hannon
}

\begin{abstract}
Periodic cleaning of the end faces of fiber optic cable links in aircraft avionics systems is undertaken as part of routine maintenance or when problems develop. Aeronautical Radio Incorporated (ARINC) has established guidelines for the installation and cleaning of fiber optic cables and components in its standards and a number of isopropyl alcohol based fiber optic cleaning kits are available on the commercial market. While these kits and techniques have proven successful in maintaining signal integrity over the short term, an industry standard as to the effects of repetitive cleaning operations has not been well established. The purpose of this study is to evaluate the effects of repeated end face cleaning on cable transmissivity and make this data available to the industry. It is anticipated the results will provide information useful to the overall determination of cable life cycles enhancing the safety and integrity of fiber optics usage in aircraft avionics systems.
\end{abstract}

\section{Introduction}

As part of a study recently undertaken at the Southern Illinois University Department of Aviation Technologies, effects of short term exposure to common aircraft chemicals and solvents on fiber optic cable transmissivity were evaluated to determine the level of degradation occurring due to chemical activity if any. Test groups of cables and controls were prepared, ST type connectors attached, and baseline values of cable transmissivity measured and recorded. Following short term exposure ( 1 week) to various solvents and chemicals, the cables were retested and the results recorded and evaluated. As part of the test regimen, the cable ends were cleaned using Aeronautical Radio Incorporated (ARINC) accepted methods following initial preparation and after exposure to the various test chemicals. In the control portion of the study, one set of cables was exposed to a typical isopropyl alcohol cleaning chemical for one week and subjected to the same standard regimen performed on all the test samples. No significant short term effects on the cleaning chemical control set were noted in the study (Hannon and Ramsundar, 2007).
Since fiber optic cable ends in aerospace applications are cleaned prior to installation, at periodic maintenance intervals, or when problems arise, it is conceivable that the effects of repetitive cleaning may be detrimental to long term cable performance. The aerospace industry, through contacts with Boeing Aerospace in St. Louis, MO, desired information on the extent of these effects if any (Boeing, 2007). In order to satisfy this request, an evaluation of the long term effects of repetitive cable end cleaning was undertaken wherein cables were subjected to over 100 cleaning cycles over a seven and one half month period.

\section{Study Protocol}

This research consisted of evaluation of 10 meter lengths of polymethyl methacrylate (PMMA) plastic core fiber optic cable as may typically be used in aircraft installations. The cable specimens were cut to the specified lengths and categorized. Following initial preparation, ST type connectors were mounted on the cables and the end faces polished, cleaned, inspected, and initially tested to establish a baseline transmissivity level. Appropriate controls were run in parallel with the testing 
operation. Testing procedures followed the guidelines outlined in Aeronautical Radio Incorporated Project Paper 805: Fiber Optic Test Procedures and the repetitive cleanings were performed in accordance with ARINC Project Paper 806: Fiber Optic Installation and Maintenance Procedures (ARINC, 2005) and Cisco Systems brochure on inspection and cleaning procedures for fiber optic connections (Cisco Systems, 2006).

The cable samples and controls were periodically subjected to the standardized cleaning regimen and transmissivity tests at intervals not exceeding once per day over a period of $7 \quad 1 / 2$ months. A fiber optic transmissivity test set employing $650 \eta \mathrm{M}$ wavelength red light was used for determination of cable performance. Source illumination of $650 \eta \mathrm{M}$ is the wavelength normally employed for data transmission in $1 \mathrm{~mm}$ plastic fiber optic cable. An ambient temperature and relative humidity reading was also taken concurrently with each test cycle. Test, temperature, and relative humidity results were logged and documented in accordance with sound research practices and accepted scientific method. The step by step procedure for cleaning, inspection and testing of the cables was well documented and a checklist used to assure consistency and repeatability. Errors due to inadvertent mechanical abrasion or end compression were mitigated through careful handing of the cable samples and use of dust covers on the ST connector ends. Several transmissivity test readings were taken at each test interval and averaged to help alleviate any inherent test set measurement or interpretation errors.

Cable transmissivity before and after cleaning at each test interval and over time was measured in microwatts and recorded. The data was then transferred to an Excel ${ }^{\circledR}$ spreadsheet and graphed for documentation, study, and interpretation. Values representing the power transmitted through the cables prior to, after and throughout the successive cleaning regimens were recorded and statistical analyses conducted using both Excel® and SPSS $®$ where thought relevant.

\section{Materials}

\section{Durable Materials:}

Fiber Optic Test Set; Manufacturer: Industrial Fiber Optics \#IF-FOM

Fiber Optic Microscope 100X; Manufacturer: Fiber Optics Instruments Sales, Inc

Fiber Optic Tool Kit; Manufacturer: Industrial Fiber Optics \#IF-TK4

Professional Fiber Cutter; Manufacturer: Industrial Fiber Optics \#IF-FC1
'ST' ferrule Polishing puck

Glass Polishing Plate

Fiber Optic/ Wire Stripper 766-A; Manufacturer:

Fiber Optic Instruments Sales, Inc

ST Connector Crimping Tool

4-oz Water Dispenser

Consumables:

ST (Straight Tip) Connectors

PMMA $1 \mathrm{~mm}$ Fiber Optic Cable (see specifications, Appendix E)

99\% Isopropyl Alcohol

Bleached White Cotton Head Swabs

Distilled Water

Sanitary Cleaning Tissue

$3 \mu \mathrm{M}$ Polishing Film

2000-grit Polishing Paper

KEEN Single-Edge Razor Blades

\section{Cleaning Methodology}

Thorough cleaning was performed consistently using the cotton swab and isopropyl alcohol method as described below:

Dip cotton swab into bottle of $99 \%$ isopropyl alcohol.

Vigorously shake off excess alcohol from the swab to prevent residue.

Hold the fiber vertically so the fiber surface points upward and carefully place the base of the swab against the fiber optic surface.

Drag the swab across the fiber optic surface in a single stroke. Do not drag the swab back and forth.

Repeat from step 4, using the other side of the swab.

Check fiber cable with fiberscope to ensure the fiber if free from cleaning solvent residue and cotton fibers.

\section{Results}

Repetitive cable cleanings and transmissivity testing were conducted during the period of early September, 2007 through mid-April, 2008. Figure 1 depicts all the parameters examined including temperature and humidity of the testing environment over the $7 \mathrm{1} / 2$ month testing period. While the relationship between the before and after cleaning tests and unaltered control appear fairly flat throughout the testing period, some interesting variances were noted. Although some of these were not directly related to the goals of the research, 
statistical analyses were run as an aid in determining significance of the variances and are conveyed below. It was noted that while the ambient temperature remained fairly constant $\left(66-70^{\circ} \mathrm{F}\right.$; mean of $70^{\circ}$, standard deviation $2.5^{\circ}$ ) and appeared to have no effect on cable performance, relative humidity fuctuated widely from less than $15 \%$ to over $50 \%$ supporting the fact that the testing enviromment lacked humidity control and changed with prevailing weather conditions. Humidity levels under
$15 \%$ were below the range of the measuring instrument and therefore may have been actually lower than indicated. As depicted in Figure 1, the middle to the near right hand portion of the horizontal axis from about cycle 36 to 90 represents testing performed in the winter months when humidity in the Midwestern part of the U.S. is low and heated indoor spaces without added moisture can become very dry.

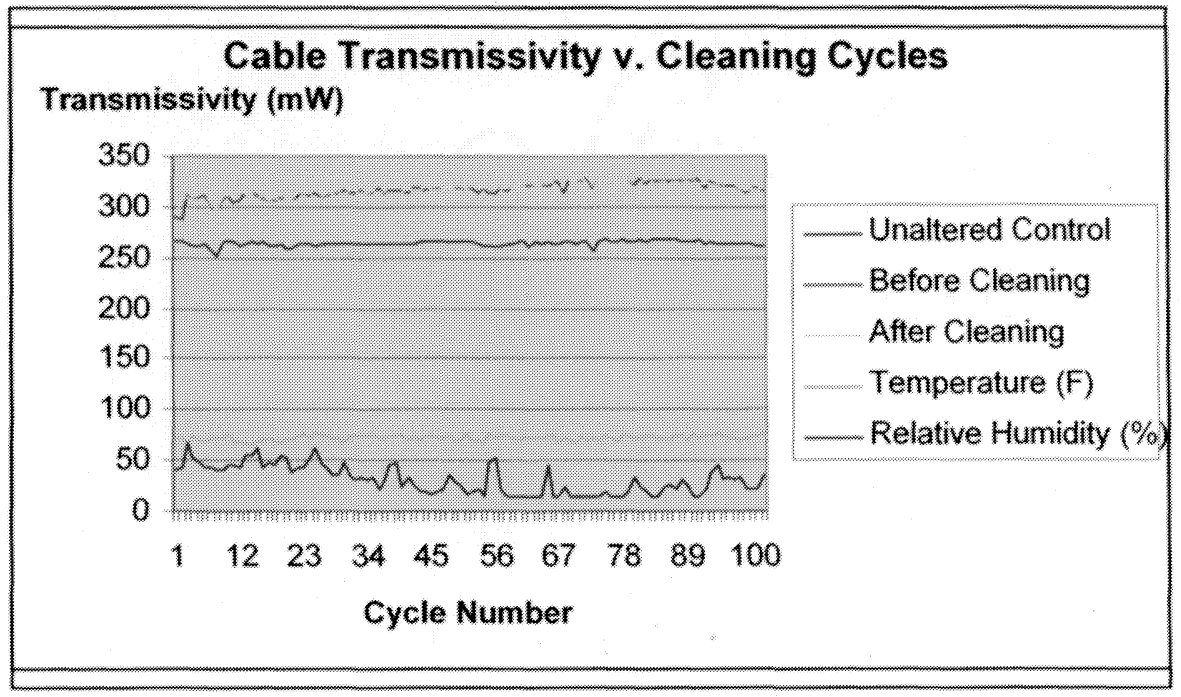

Figure 1. Transmissivity, temperature and humidity

In Figure 2 , when the quantification scale representing transmissivity is examined, there is an apparent increase in the middle portion of the testing cycle followed by an apparent decrease in transmissivity. The unaltered control appears to correlate with this change as well. As noted above, the middle portions of the graph represent the winter months when humidity is low and the right hand portion corresponds to the beginning of spring and the onset of higher humidity days. As warmer weather ensues, building air conditioning turns on and the humidity drops again. 


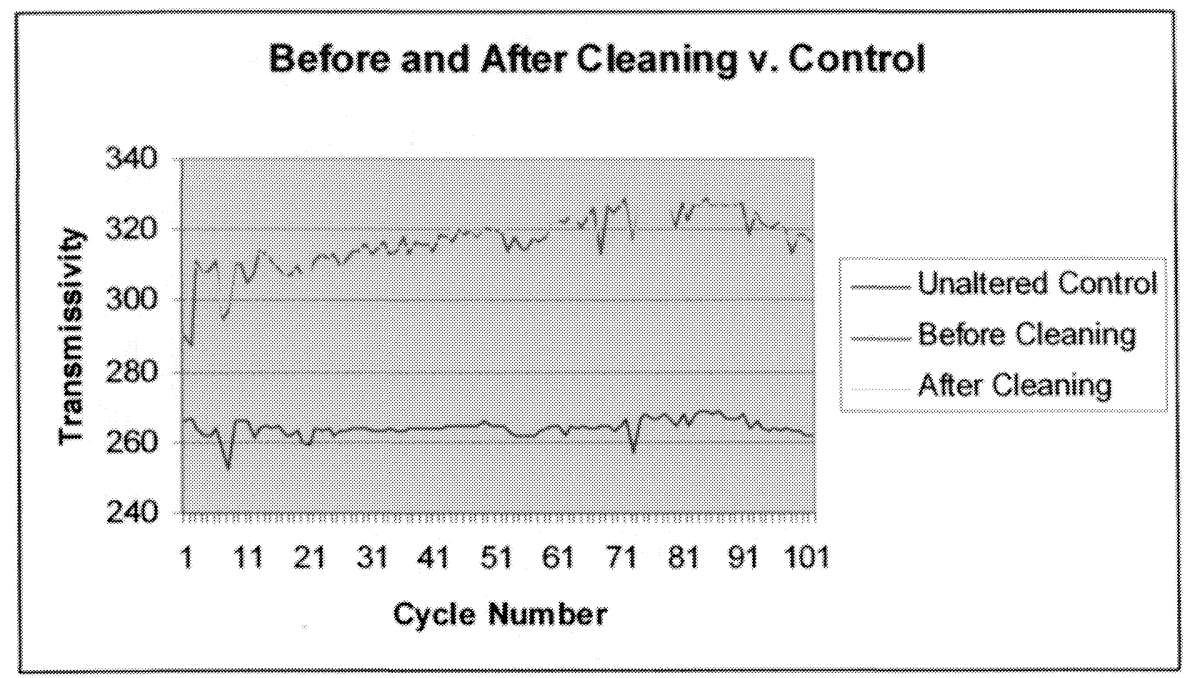

Figure 2. Transmissivity correlated with the unattered control

Figure 3 shows the correlation between transmissivity following each cleaning cycle with relative humidity noting the slight inverse relationship between the two parameters.

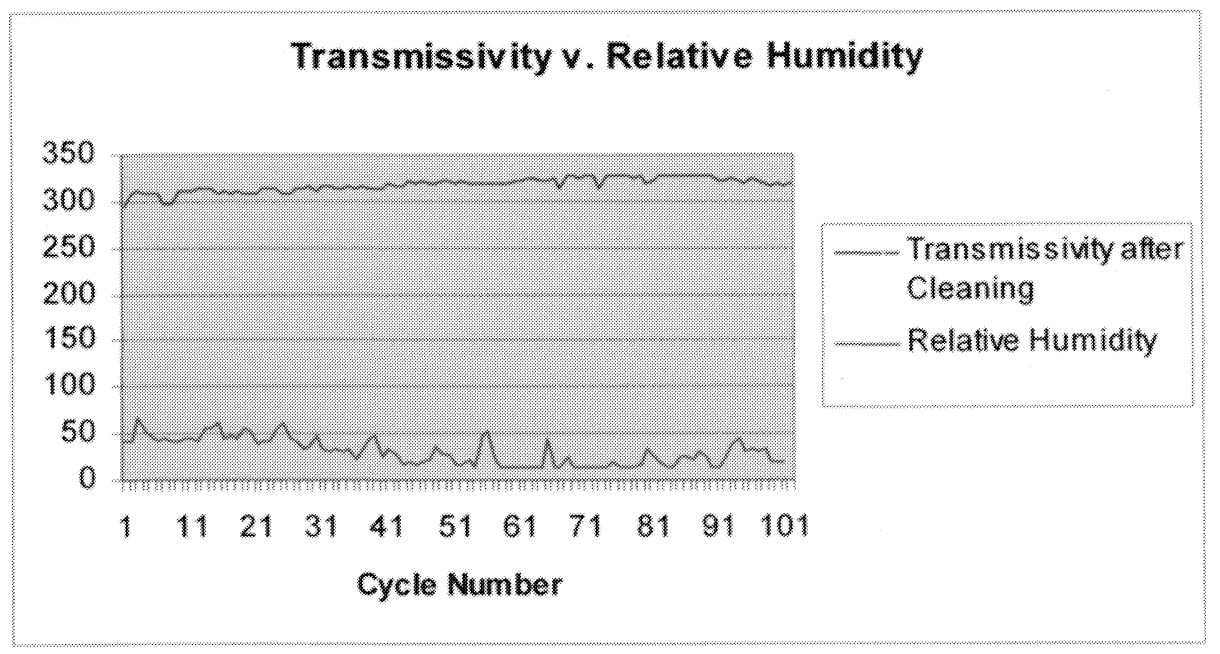

Figure3. After cleaning transmissivity correlated with relative humidity 
The general increase in transmissivity with decreasing humidity is further exemplified by the scatter plot and trend line shown in Figures 4 and 5.

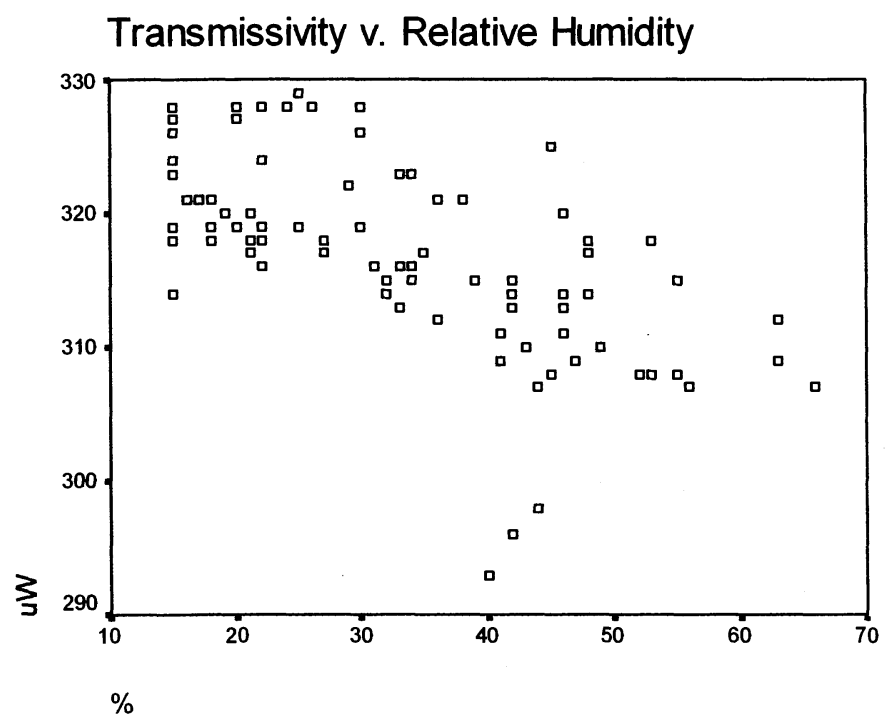

Figure 4. Scatterplot of after cleaning with relative humidity

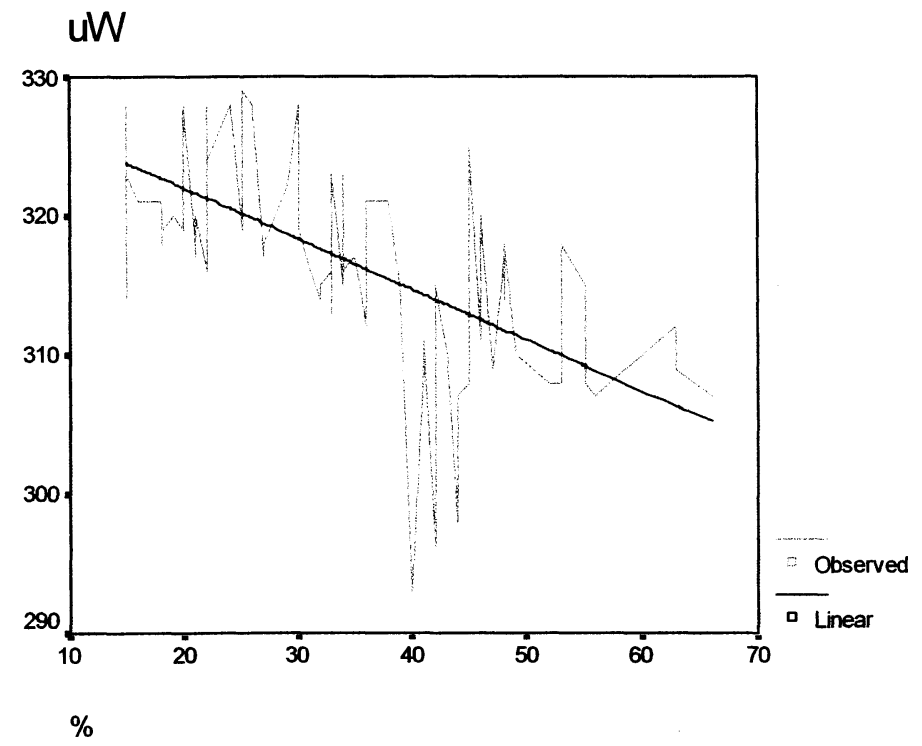

Figure 5. Trendline of after cleaning with relative humidity 
In spite of the slight fluctuations in cable performance apparently related to humidity variations, it was noted that the three transmissivity test parameters consisting of before cleaning, after cleaning and the unaltered control remained fairly constant with respect to each other over the entire test period. The mean values for before cleaning and after cleaning cable transmissivity were 317 and 318 $\mu \mathrm{W}$ respectively. Standard deviation calculations run on all three transmissivity variables were as follows: unaltered control: 2.5, before cleaning: 8.6, and after cleaning: 7.4 each representing less than $5 \%$ variation from the mean of their value spread. Linear regression of humidity as an independent variable versus transmissivity as the dependent variable suggested a statistically significant inverse relationship between relative humidity and cable transmissivity as depicted in the data in Table 1. Since variance was slight and correlated similarly both in the before and after cleaning test samples and controls it was felt to be unrelated to the effects of the multiple cleaning cycles on transmissivity. Nevertheless, the apparent linear inconsistency did warrant further investigation.

Table 1. Coefficieints of variants humidity v. transmissivity

Coefficients

\begin{tabular}{|r|r|r|r|r|r|r|}
\hline & $\begin{array}{r}\text { Unstandardized } \\
\text { Cooefficients }\end{array}$ & & $\begin{array}{r}\text { Standardized } \\
\text { Coefficients }\end{array}$ & Sig \\
\hline Model 1 & & B & Std Error & Beta & & \\
\hline 1 & (constant) & 329.246 & 1.311 & & 251.065 & .000 \\
\hline & $\%$ & -.363 & .038 & -.686 & -9.458 & .000 \\
\hline
\end{tabular}

a. Dependent Variable: $u$ W

\section{Conclusion}

Based on the data revealed in the study and further investigation of a slight linear variance related to ambient humidity, it was apparent that repetitive thorough cable end face cleaning using the cotton swab and $99 \%$ isopropyl alcohol method had little effect on fiber optic cable transmissivity. While minor ambient temperature variations occurred, no temperature related effects on cable transmissivity were evident. It should be noted that the cable ends were not subject to environmental contaminants such as heavy dust, dirt, sand, volatile chemicals, etc. as may be present in an aircraft operating environment. Repetitive cleaning of the cable ends at the connectors to the extent examined in this study did not constitute a detriment to performance. Whether repetitive cleaning effects on cables in more hostile environments, such as may be encountered desert or very dusty conditions, remains benign requires further investigation. Additional research is planned to be undertaken in this regard. $\rightarrow$

Dennis R. Hannon is currently an assistant professor at the College of Applied Science and Art in the Department of Aviation Technologies at Southern Illinois University, Carbondale.. He holds a B.S. in Biological Sciences from Loyola University, a B.S. in Aviation Technology from Southern Illinois University Carbondale, and a M.P.A. from Southern Illinois University. He began at SIU as term assistant instructor of avionics in January, 2002 and accepted a position as continuing assistant professor August 2007. He began performing fiber optics research in August 2007 and incorporated undergraduate students into the research process at the same time.. 


\section{References}

ARINC. (2005). ARINC project paper 806; Fiber optic installation and maintenance procedures. Annapolis: Aeronautical Radio Incorporated.

ARINC. (2005). ARINC project paper 805; Fiber optic test procedures.Annapolis: Aeronautical Radio Incorporated

Boeing Aerospace Company. (2007, August). Personal communication by the author with Harry Fanning, II of Boeing regarding the desire for information on cable performance following repetitive cleaning procedures.

Cisco Systems, Inc. (2006). Brochure: Inspection and cleaning procedures for fiber optic connections. Document ID: 51834

Hannon, D. and Ramsundar, A. (2007). A preliminary study into the effects of common aircraft chemicals and solvents on fiber optic cable transmissivity. Aviation Technical Education Journal, 29(2), 4-11. 
Journal of Aviation/Aerospace Education \& Research, Vol. 19, No. 3 [2010], Art. 4

https://commons.erau.edu/jaaer/vol19/iss3/4 